\title{
Application of fixed point theory for approximating of a positive-additive functional equation in intuitionistic random $C^{*}$-algebras
}

Javad Vahidi

Department of Mathematics, Iran University of Science and Technology, Tehran, Iran.

Communicated by C. Park

\begin{abstract}
We apply a fixed point theorem for approximating of a positive-additive functional equation in intuitionistic random $\mathrm{C}^{*}$ algebras. (c) 2017 All rights reserved.
\end{abstract}

Keywords: Approximation, fixed point theory, intuitionistic, random normed spaces, $\mathrm{C}^{*}$-algebra. 2010 MSC: 47H10.

\section{Introduction and preliminaries}

The concept of distribution function and survival functions was introduced by Abdu et al. [1] and Saadati et al. [18]. Using these functions the authors defined intuitionistic random $C^{*}$-algebras and gave some properties and example of these spaces also for more results on stability please see $[4,5,9,10,12$ $15,17,19,20]$.

A metric $d$ on non empty set $\Omega$ with rage $[0, \infty]$ is called a generalized metric.

Theorem 1.1 ([6]). Assume that $\mathrm{J}: \Omega \rightarrow \Omega$ be a contractive mapping with Lipschitz constant $\mathrm{L}<1$ on generalized metric space $(\Omega, d)$. Then for $x \in \Omega$, either $d\left(J^{n} x, J^{n+1} x\right)=\infty$ for all nonnegative integers $n$ or there exists a positive integer $n_{0}$ such that

(1) $d\left(J^{n} x, J^{n+1} x\right)<\infty, \quad \forall n \geqslant n_{0}$;

(2) the sequence $\left\{\mathrm{J}^{\mathrm{n}} \mathrm{x}\right\}$ converges to a fixed point $\mathrm{y}^{*}$ of $\mathrm{J}$;

(3) $y^{*}$ is the unique fixed point of $\mathrm{J}$ in the set $\Gamma=\left\{\mathrm{y} \in \Omega \mid \mathrm{d}\left(\mathrm{J}^{\mathrm{n}_{0}} \mathrm{x}, \mathrm{y}\right)<\infty\right\}$;

(4) $d\left(y, y^{*}\right) \leqslant \frac{1}{1-L} d(y, J y)$ for all $y \in \Gamma$.

Definition $1.2([7])$. Let $\left(A, \mathcal{P}_{\mu, v}, \mathcal{T}, \mathcal{T}^{\prime}\right)$ be an intuitionistic random Banach algebra $C^{*}$-algebra and $x \in A$ a self-adjoint element, i.e., $x^{*}=x$. Then $x$ is said to be positive if it is of the form $y y^{*}$ for some $y \in A$.

The set of positive elements of $A$ is denoted by $A^{+}$.

Email address: jvahidi@iust.ac.ir (Javad Vahidi)

doi:10.22436/jnsa.010.05.11 
Note that $A^{+}$is a closed convex cone (see [7]).

It is well-known that for a positive element $x$ and a positive integer $n$ there exists a unique positive element $y \in A^{+}$such that $x=y^{n}$. We denote $y$ by $x^{\frac{1}{n}}$ (see [8]).

In this paper, we introduce the following functional equation

$$
\mathrm{T}\left(\left(x^{\frac{1}{m}}+y^{\frac{1}{m}}\right)^{\mathrm{m}}\right)=\left(\mathrm{T}(x)^{\frac{1}{m}}+\mathrm{T}(\mathrm{y})^{\frac{1}{m}}\right)^{\mathrm{m}},
$$

for all $x, y \in A^{+}$and a fixed integer $m$ greater than 1 , which is called a positive-additive functional equation. Each solution of the positive-additive functional equation is called a positive-additive mapping, in which the function $f(x)=c x, \quad c \geqslant 0$, in the set of non-negative real numbers is a solution of the functional equation (1.1).

Throughout this paper, let $\mathrm{A}^{+}$and $\mathrm{B}^{+}$be the sets of positive elements in intuitionistic random $\mathrm{C}^{*}$ algebras $(A, N)$ and $(B, N)$, respectively. Assume that $m$ is a fixed integer greater than 1 .

\section{Stability of the positive-additive functional equation (1.1): fixed point approach}

Lemma 2.1 ([16]). Let $\mathrm{T}: \mathrm{A}^{+} \rightarrow \mathrm{B}^{+}$be a positive-additive mapping satisfying (1.1). Then $\mathrm{T}$ satisfies

$$
\mathrm{T}\left(2^{\mathrm{mn}} x\right)=2^{\mathrm{mn}} \mathrm{T}(\mathrm{x}),
$$

for all $\mathrm{x} \in \mathrm{A}^{+}$and all $\mathrm{n} \in \mathbb{Z}$.

Using the fixed point method, we prove the Hyers-Ulam stability of the positive-additive functional equation (1.1) in intuitionistic random $\mathrm{C}^{*}$-algebras.

Note that the fundamental ideas in the proofs of the main results in this section are contained in $[2,3]$.

Theorem 2.2. Let $\varphi: A^{+} \times A^{+} \times(0, \infty) \rightarrow L^{*}$ be a function such that there exists an $E<1$ with

$$
\varphi(x, y, t) \geqslant_{L} \varphi\left(2^{m} x, 2^{m} y, \frac{2^{m} t}{E}\right)
$$

for all $\mathrm{x}, \mathrm{y} \in \mathrm{A}^{+}$and $\mathrm{t}>0$. Let $\mathrm{f}: \mathrm{A}^{+} \rightarrow \mathrm{B}^{+}$be a mapping satisfying

$$
\mathcal{P}_{\mu, v}\left(f\left(\left(x^{\frac{1}{m}}+y^{\frac{1}{m}}\right)^{m}\right)-\left(f(x)^{\frac{1}{m}}+f(y)^{\frac{1}{m}}\right)^{m}, t\right) \geqslant_{L} \varphi(x, y, t),
$$

for all $\mathrm{x}, \mathrm{y} \in \mathrm{A}^{+}$and $\mathrm{t}>0$. Then there exists a unique positive-additive mapping $\mathrm{T}: \mathrm{A}^{+} \rightarrow \mathrm{A}^{+}$satisfying (1.1) and

$$
\mathcal{P}_{\mu, v}(f(x)-T(x), t) \geqslant_{L} \varphi\left(x, x, \frac{\left(2^{m}-2^{m} L\right) t}{E}\right)
$$

for all $\mathrm{x} \in \mathrm{A}^{+}$and $\mathrm{t}>0$.

Proof. Letting $y=x$ in (2.2), we get

$$
\mathcal{P}_{\mu, v}\left(f\left(2^{m} x\right)-2^{m} f(x), t\right) \geqslant_{L} \varphi(x, x, t),
$$

for all $x \in A^{+}$and $t>0$.

Consider the set

$$
X:=\left\{g: A^{+} \rightarrow B^{+}\right\}
$$

and introduce the generalized metric on $\mathrm{X}$ :

$$
d(g, h)=\inf \left\{\mu \in \mathbb{R}_{+}: \mathcal{P}_{\mu, v}(g(x)-h(x), t) \geqslant_{L} \varphi\left(x, x, \frac{t}{\mu}\right), \quad \forall x \in A^{+}, \quad t>0\right\},
$$


where, as usual, $\inf \phi=+\infty$. It is easy to show that $(X, d)$ is complete (see [11]).

Now, we consider the linear mapping $\mathrm{J}: \mathrm{X} \rightarrow \mathrm{X}$ such that

$$
J g(x):=2^{m} g\left(\frac{x}{2^{m}}\right)
$$

for all $x \in A^{+}$.

Let $g, h \in X$ be given such that $d(g, h)=\varepsilon$. Then

$$
\mathcal{P}_{\mu, v}(g(x)-h(x), t) \geqslant_{L} \varphi(x, x, t),
$$

for all $x \in A^{+}$and $t>0$. Hence

$$
\mathcal{P}_{\mu, v}(J g(x)-J h(x), t)=\mathcal{P}_{\mu, v}\left(2^{m} g\left(\frac{x}{2^{m}}\right)-2^{m} h\left(\frac{x}{2^{m}}\right), t\right) \geqslant_{L} \varphi\left(x, x, \frac{t}{E}\right),
$$

for all $x \in A^{+}$and $t>0$. So $d(g, h)=\varepsilon$ implies that $d(J g, J h) \leqslant E \varepsilon$. This means that

$$
d(J g, J h) \leqslant E d(g, h)
$$

for all $g, h \in X$.

It follows from (2.4) that

$$
\mathcal{P}_{\mu, v}\left(f(x)-2^{m_{f}}\left(\frac{x}{2^{m}}\right), t\right) \geqslant_{L} \varphi\left(x, x, \frac{2^{m} t}{E}\right),
$$

for all $x \in A^{+}$and $t>0$. So $d(f, J f) \leqslant \frac{L}{2^{m}}$.

By Theorem 1.1, there exists a mapping $\mathrm{T}: \mathrm{A}^{+} \rightarrow \mathrm{B}^{+}$satisfying the following:

(1) $\mathrm{T}$ is a fixed point of $J$, i.e.,

$$
\mathrm{T}\left(\frac{x}{2^{\mathrm{m}}}\right)=\frac{1}{2^{\mathrm{m}}} \mathrm{T}(\mathrm{x}),
$$

for all $x \in A^{+}$. The mapping $T$ is a unique fixed point of $J$ in the set

$$
M=\{g \in X: d(f, g)<\infty\} .
$$

This implies that $T$ is a unique mapping satisfying (2.5) such that there exists a $\mu \in(0, \infty)$ satisfying

$$
\mathcal{P}_{\mu, v}(f(x)-T(x), t) \geqslant_{L} \varphi\left(x, x, \frac{t}{\mu}\right),
$$

for all $x \in A^{+}$and $t>0$;

(2) $d\left(J^{n} f, T\right) \rightarrow 0$ as $n \rightarrow \infty$. This implies the equality

$$
\lim _{n \rightarrow \infty} 2^{m n} f\left(\frac{x}{2^{m n}}\right)=T(x)
$$

for all $x \in A^{+}$;

(3) $d(f, T) \leqslant \frac{1}{1-E} d(f, J f)$, which implies the inequality

$$
d(f, T) \leqslant \frac{E}{2^{m}-2^{m E}} .
$$

This implies that the inequality (2.3) holds. 
By (2.1) and (2.2),

$$
\begin{aligned}
\mathcal{P}_{\mu, v} & \left(f\left(\frac{\left(x^{\frac{1}{m}}+y^{\frac{1}{m}}\right)^{m}}{2^{m n}}\right)-\left(\left(2^{m n} f\left(\frac{x}{2^{m n}}\right)\right)^{\frac{1}{m}}+\left(2^{m n} f\left(\frac{y}{2^{m n}}\right)\right)^{\frac{1}{m}}\right)^{m}, \frac{t}{2^{m n}}\right) \\
& \geqslant_{L} \varphi\left(\frac{x}{2^{m n}}, \frac{y}{2^{m n}}, \frac{t}{2^{m n}}\right) \\
& \geqslant_{L} \varphi\left(x, y, \frac{t}{L^{m n}}\right),
\end{aligned}
$$

for all $x, y \in A^{+}$, all $n \in \mathbb{N}$ and $t>0$. So

$$
\mathcal{P}_{\mu, v}\left(T\left(\left(x^{\frac{1}{m}}+y^{\frac{1}{m}}\right)^{m}\right)-\left(T(x)^{\frac{1}{m}}+T(y)^{\frac{1}{m}}\right)^{m}, t\right)=1_{\mathcal{L}},
$$

for all $x, y \in A^{+}$and $t>0$. Thus the mapping $T: A^{+} \rightarrow B^{+}$is positive-additive, as desired.

Corollary 2.3. Let $\mathrm{p}>1$ and $\theta_{1}, \theta_{2}$ be non-negative real numbers, and let $\mathrm{f}: \mathrm{A}^{+} \rightarrow \mathrm{B}^{+}$be a mapping such that

$$
\begin{aligned}
\mathcal{P}_{\mu, v} & \left(f\left(\left(x^{\frac{1}{m}}+y^{\frac{1}{m}}\right)^{m}\right)-\left(f(x)^{\frac{1}{m}}+f(y)^{\frac{1}{m}}\right)^{m}, t\right) \\
& \geqslant L \\
& \left.t \frac{t}{t+\theta_{1}\left(\|x\|^{p}+\|y\|^{p}\right)+\theta_{2} \cdot\|x\|^{\frac{p}{2}} \cdot\|y\|^{\frac{p}{2}}}, \frac{\theta_{1}\left(\|x\|^{p}+\|y\|^{p}\right)+\theta_{2} \cdot\|x\|^{\frac{p}{2}} \cdot\|y\|^{\frac{p}{2}}}{t+\theta_{1}\left(\|x\|^{p}+\|y\|^{p}\right)+\theta_{2} \cdot\|x\|^{\frac{p}{2}} \cdot\|y\|^{\frac{p}{2}}}\right),
\end{aligned}
$$

for all $x, y \in \mathrm{A}^{+}$and $\mathrm{t}>0$. Then there exists a unique positive-additive mapping $\mathrm{T}: \mathrm{A}^{+} \rightarrow \mathrm{B}^{+}$satisfying (1.1) and

$$
\mathcal{P}_{\mu, v}(f(x)-T(x), t) \geqslant_{L}\left(\frac{t}{t+\frac{2 \theta_{1}+\theta_{2}}{2^{m p}-2^{m}}}\|x\|^{p}, \frac{\frac{2 \theta_{1}+\theta_{2}}{2^{m p}-2^{m}}}{t+\frac{2 \theta_{1}+\theta_{2}}{2^{m p}-2^{m}}}\|x\|^{p}\right),
$$

for all $\mathrm{x} \in \mathrm{A}^{+}$and $\mathrm{t}>0$.

Proof. The proof follows from Theorem 2.2 by taking

$$
\varphi(x, y, t)=\left(\frac{t}{t+\theta_{1}\left(\|x\|^{p}+\|y\|^{p}\right)+\theta_{2} \cdot\|x\|^{\frac{p}{2}} \cdot\|y\|^{\frac{p}{2}}}, \frac{\theta_{1}\left(\|x\|^{p}+\|y\|^{p}\right)+\theta_{2} \cdot\|x\|^{\frac{p}{2}} \cdot\|y\|^{\frac{p}{2}}}{t+\theta_{1}\left(\|x\|^{p}+\|y\|^{p}\right)+\theta_{2} \cdot\|x\|^{\frac{p}{2}} \cdot\|y\|^{\frac{p}{2}}}\right),
$$

for all $x, y \in A^{+}$and $t>0$. Then we can choose $E=2^{m-m p}$ and we get the desired result.

Theorem 2.4. Let $\left.\varphi: A^{+} \times A^{+} \times(0, \infty)\right] \rightarrow L^{*}$ be a function such that there exists an $E<1$ with

$$
\varphi(x, y, t) \geqslant_{L} \varphi\left(\frac{x}{2^{m}}, \frac{y}{2^{m}}, \frac{t}{2^{m} E}\right)
$$

for all $\mathrm{x}, \mathrm{y} \in \mathrm{A}^{+}$and $\mathrm{t}>0$. Let $\mathrm{f}: \mathrm{A}^{+} \rightarrow \mathrm{B}^{+}$be a mapping satisfying (2.2). Then there exists a unique positive-additive mapping $\mathrm{T}: \mathrm{A}^{+} \rightarrow \mathrm{A}^{+}$satisfying (1.1) and

$$
\mathcal{P}_{\mu, v}(f(x)-T(x), t) \geqslant_{L} \varphi\left(x, x,\left(2^{m}-2^{m} E\right) t\right),
$$

for all $\mathrm{x} \in \mathrm{A}^{+}$and $\mathrm{t}>0$.

Proof. Let $(X, d)$ be the generalized metric space defined in the proof of Theorem 2.2.

Consider the linear mapping $\mathrm{J}: \mathrm{X} \rightarrow \mathrm{X}$ such that

$$
\operatorname{Jg}(x):=\frac{1}{2^{m}} g\left(2^{m} x\right),
$$


for all $x \in A^{+}$.

It follows from (2.4) that

$$
\mathcal{P}_{\mu, v}\left(f(x)-\frac{1}{2^{m}} f\left(2^{m} x\right), t\right) \geqslant_{L} \varphi\left(x, x, 2^{m} t\right),
$$

for all $x \in A^{+}$and $t>0$. So $d(f, J f) \leqslant \frac{1}{2^{m}}$.

The rest of the proof is similar to the proof of Theorem 2.2.

Corollary 2.5. Let $0<\mathrm{p}<1$ and $\theta_{1}, \theta_{2}$ be non-negative real numbers, and let $\mathrm{f}: \mathrm{A}^{+} \rightarrow \mathrm{B}^{+}$be a mapping satisfying (2.6). Then there exists a unique positive-additive mapping $\mathrm{T}: \mathrm{A}^{+} \rightarrow \mathrm{B}^{+}$satisfying (1.1) and

$$
\mathcal{P}_{\mu, v}(f(x)-T(x), t) \geqslant_{L}\left(\frac{t}{t+\frac{2 \theta_{1}+\theta_{2}}{2^{m}-2^{m p}}}\|x\|^{p}, \frac{\frac{2 \theta_{1}+\theta_{2}}{2^{m}-2^{m p}}}{t+\frac{2 \theta_{1}+\theta_{2}}{2^{m}-2^{m p}}}\|x\|^{p}\right),
$$

for all $x \in A^{+}$and $t>0$.

Proof. The proof follows from Theorem 2.4 by taking

$$
\varphi(x, y, t)=\left(\frac{t}{t+\frac{2 \theta_{1}+\theta_{2}}{2^{m}-2^{m p}}}\|x\|^{p}, \frac{\frac{2 \theta_{1}+\theta_{2}}{2^{m}-2^{m p}}}{t+\frac{2 \theta_{1}+\theta_{2}}{2^{m}-2^{m p}}}\|x\|^{p}\right),
$$

for all $x, y \in A^{+}$and $t>0$. Then we can choose $E=2^{m p-m}$ and we get the desired result.

\section{References}

[1] A. A. N. Abdou, Y. J. Cho, R. Saadati, Distribution and survival functions with applications in intuitionistic random Lie $C^{*}$-algebras, J. Comput. Anal. Appl., 21 (2016), 345-354.1

[2] L. Cădariu, V. Radu, On the stability of the Cauchy functional equation: a fixed point approach, Grazer Math. Ber., 346 (2004), 43-52. 2

[3] L. Cădariu, V. Radu, Fixed point methods for the generalized stability of functional equations in a single variable, Fixed Point Theory and Appl., 2008 (2008), 15 pages. 2

[4] Y. J. Cho, Th. M. Rassias, R. Saadati, Stability of functional equations in random normed spaces, Springer Optimization and Its Applications, Springer, New York, (2013). 1

[5] Y. J. Cho, R. Saadati, Lattictic non-Archimedean random stability of ACQ functional equation, Adv. Difference Equ., 2011 (2011), 12 pages. 1

[6] J. Diaz, B. Margolis, A fixed point theorem of the alternative for contractions on a generalized complete metric space, Bull. Amer. Math. Soc., 74 (1968), 305-309. 1.1

[7] J. Dixmier, C*-Algebras, North-Holland Publ. Com., Amsterdam, New York and Oxford, (1977). 1.2, 1

[8] K. R. Goodearl, Notes on Real and Complex C*-Algebras, Shiva Math. Series IV, Shiva Publ. Limited, England, (1982). 1

[9] J. I. Kang, R. Saadati, Approximation of homomorphisms and derivations on non-Archimedean random Lie C*-algebras via fixed point method, J. Inequal. Appl., 2012 (2012), 10 pages. 1

[10] S. J. Lee, R. Saadati, On stability of functional inequalities at random lattice $\phi$-normed spaces, J. Comput. Anal. Appl., 15 (2013), 1403-1412. 1

[11] D. Miheț, V. Radu, On the stability of the additive Cauchy functional equation in random normed spaces, J. Math. Anal. Appl. 343 (2008), 567-572. 2

[12] D. Miheț, R. Saadati, On the stability of the additive Cauchy functional equation in random normed spaces, Appl. Math. Lett., 24 (2011), 2005-2009.1

[13] D. Miheț, R. Saadati, S. M. Vaezpour, The stability of the quartic functional equation in random normed spaces, Acta Appl. Math., 110 (2010), 797-803.

[14] M. Mohamadi, Y. J. Cho, C. Park, P. Vetro, R. Saadati, Random stability on an additive-quadratic-quartic functional equation, J. Inequal. Appl., 2010 (2010), 18 pages.

[15] C. Park, M. Eshaghi Gordji, R. Saadati, Random homomorphisms and random derivations in random normed algebras via fixed point method, J. Inequal. Appl., 2012 (2012), 13 pages. 1

[16] C. Park, H. A. Kenary, S. Og Kim, Positive-additive functional equations in C*-algebras, Fixed Point Theory, 13 (2012), 613-622.2.1 
[17] J. M. Rassias, R. Saadati, Gh. Sadeghi, J. Vahidi, On nonlinear stability in various random normed spaces, J. Inequal. Appl., 2011 (2011), 17 pages. 1

[18] R. Saadati, Th. M. Rassias, Y. J. Cho, Z. H. Wang, Distribution and survival functions and application in intuitionistic random approximation, Appl. Math. Inf. Sci., 9 (2015), 2535-2540. 1

[19] R. Saadati, S. M. Vaezpour, Y. J. Cho, A note to paper "On the stability of cubic mappings and quartic mappings in random normed spaces" , J. Inequal. Appl., 2009 (2009), 6 pages. 1

[20] J. Vahidi, C. Park, R. Saadati, A functional equation related to inner product spaces in non-Archimedean L-random normed spaces, J. Inequal. Appl., 2012 (2012), 16 pages. 1 